\title{
Transthoracic Echocardiographic Findings of Stanford Type A Aortic Dissection: A Case Report
}

Alexandra Craen ${ }^{1}$, Javier Rosario ${ }^{1}$, Kendra Amico ${ }^{1}$, Mihir Tak ${ }^{1}$, Latha Ganti ${ }^{2,}, 3,4$

1. Emergency Medicine, University of Central Florida College of Medicine, Orlando, USA 2. Emergency Medicine, Envision Physician Services, Orlando, USA 3. Emergency Medicine, University of Central Florida College of Medicine/Hospital Corporation of America Graduate Medical Education Consortium of Greater Orlando, Orlando, USA

4. Emergency Medicine, Polk County Fire Rescue, Bartow, USA

Corresponding author: Alexandra Craen, alexandra.craen@ucf.edu

\begin{abstract}
Aortic dissection is a well-known, but relatively uncommon diagnosis in the emergency department (ED). With a mortality rate as high as 30 percent, it is important to be able to diagnose quickly and accurately. Definitive diagnosis with imaging studies such as computed tomography angiogram (CTA) can be expensive and time-consuming and may not always be available in the community. Herein, we discuss a case of a 59year-old man presenting with severe chest pain, hypotension, and bradycardia who was diagnosed with aortic dissection first by bedside ultrasound. This expedited the CTA and a cardiothoracic surgery consult, leading to a successful emergent aortic repair.
\end{abstract}

Received 11/13/2019

Review began 11/13/2019 Review ended 11/18/2019 Published 11/20/2019

() Copyright 2019 Craen et al. This is an open access article distributed under the terms of the Creative Commons Attribution License CC-BY 3.0., which permits unrestricted use, distribution, and reproduction in any medium, provided the original author and source are credited.
Categories: Cardiac/Thoracic/Vascular Surgery, Emergency Medicine Keywords: aortic dissection, ultrasound

\section{Introduction}

Aortic dissection is a relatively rare emergency with a high mortality rate, making early diagnosis and treatment essential in the emergency department (ED). The incidence of aortic dissection is around three per 100,000 with a mortality rate of 25 to 30 percent [1-3]. It is most commonly seen in men in their 60 s, and hypertension is the most common predisposing factor [3]. It can have variable presentations that make diagnosis difficult. Sudden-onset tearing chest pain, mediastinal or aortic widening on chest radiography, and pulse or blood pressure differentials were found to be independent predictors [4]. The Stanford system is the most used anatomic classification system for aortic dissections. Any dissection involving the ascending aorta is considered type A and all others are type B. Type A dissections are a surgical emergency and type B dissections are usually managed medically [3].

\section{Case Presentation}

A 59-year-old male with a past medical history of tobacco and marijuana use, chronic back pain not on narcotics, and untreated hypertension and dyslipidemia was transferred from an outside hospital for further workup after presenting there with acute substernal chest pain radiating to his anterior neck. He was found to be hypotensive and bradycardic with a blood pressure of $70 \mathrm{~s} / 40 \mathrm{~s}$ and a heart rate in the $40 \mathrm{~s}$. He was given atropine in route and on arrival received a normal saline bolus, morphine, ondansetron, and lorazepam for his symptoms. The electrocardiogram showed sinus bradycardia with no ST-segment elevations. Chest radiography showed a mildly enlarged cardiac silhouette with no acute abnormalities. Labs were significant for a negative troponin and an elevated D dimer to $35 \mathrm{mg} / \mathrm{L} \mathrm{FEU}$. He was transferred to our facility because their CT scan was not functioning.

On arrival, the patient had a blood pressure of $114 / 45$ with a heart rate of $54 \mathrm{bpm}$. He continued to have constant chest pain. On physical exam, he had normal heart sounds and equal radial and femoral pulses. His blood pressure could not initially be obtained on the right upper extremity, but after being taken manually was similar to the left. His electrocardiogram showed low voltage sinus bradycardia, and so a bedside transthoracic echo (TTE) was done. This showed a dilated aortic root with an intimal flap suggestive of aortic dissection (Figures 1,2). 


\section{Cureus}

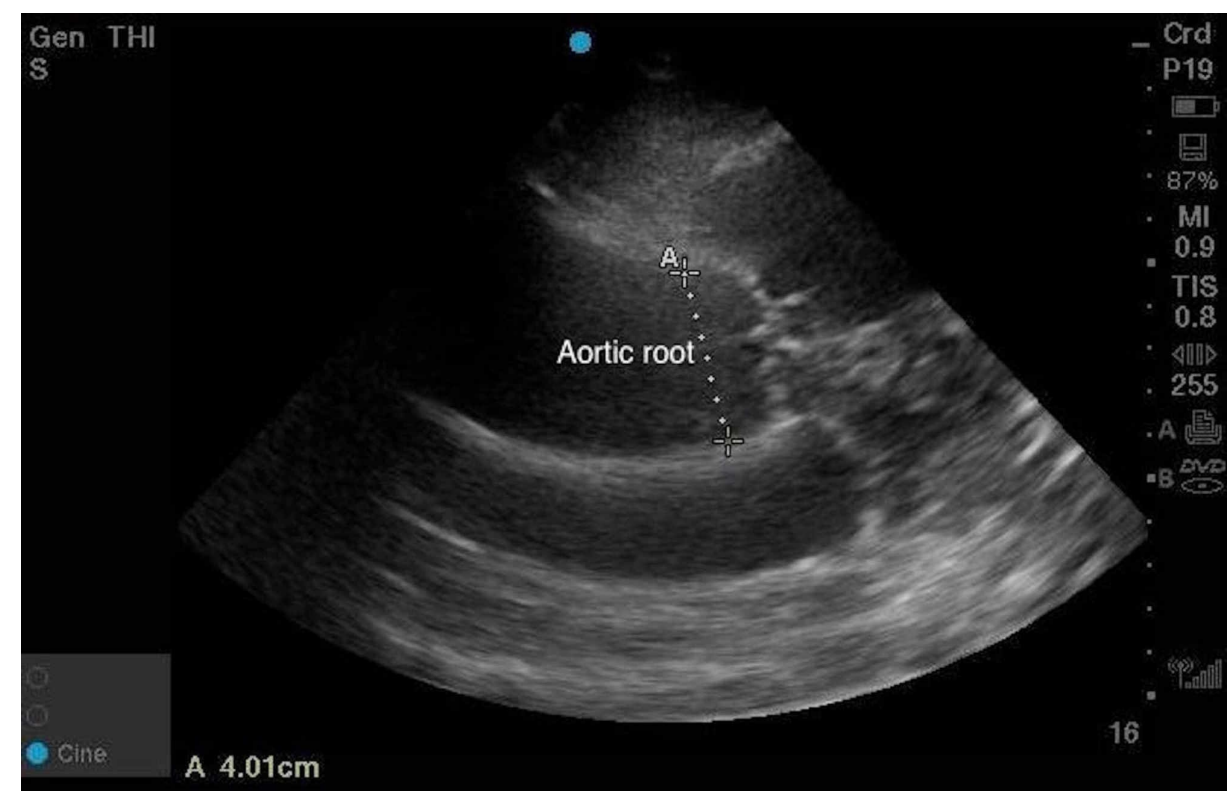

FIGURE 1: Ultrasound image of dilated aortic root

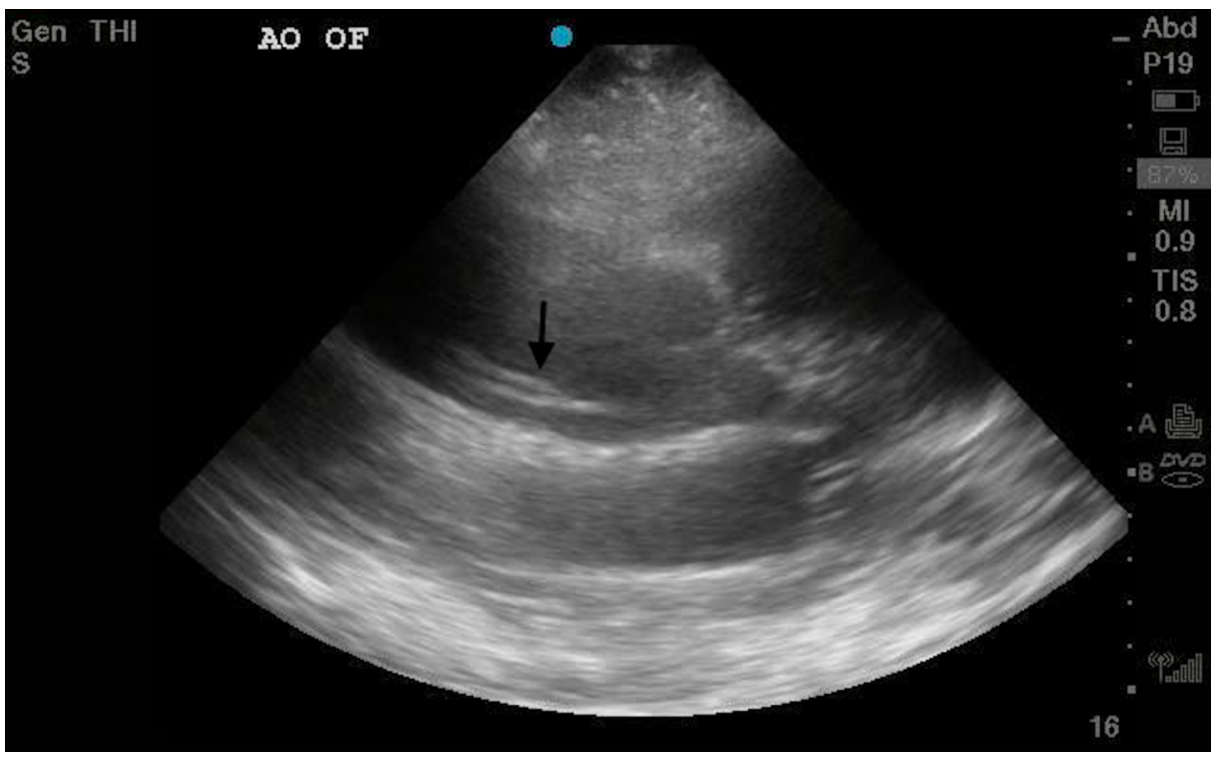

FIGURE 2: Ultrasound image of an intimal flap by the aortic root

The abdominal aorta was then evaluated and also showed a flap extending to the renal arteries (Figures 3,4). 


\section{Cureus}

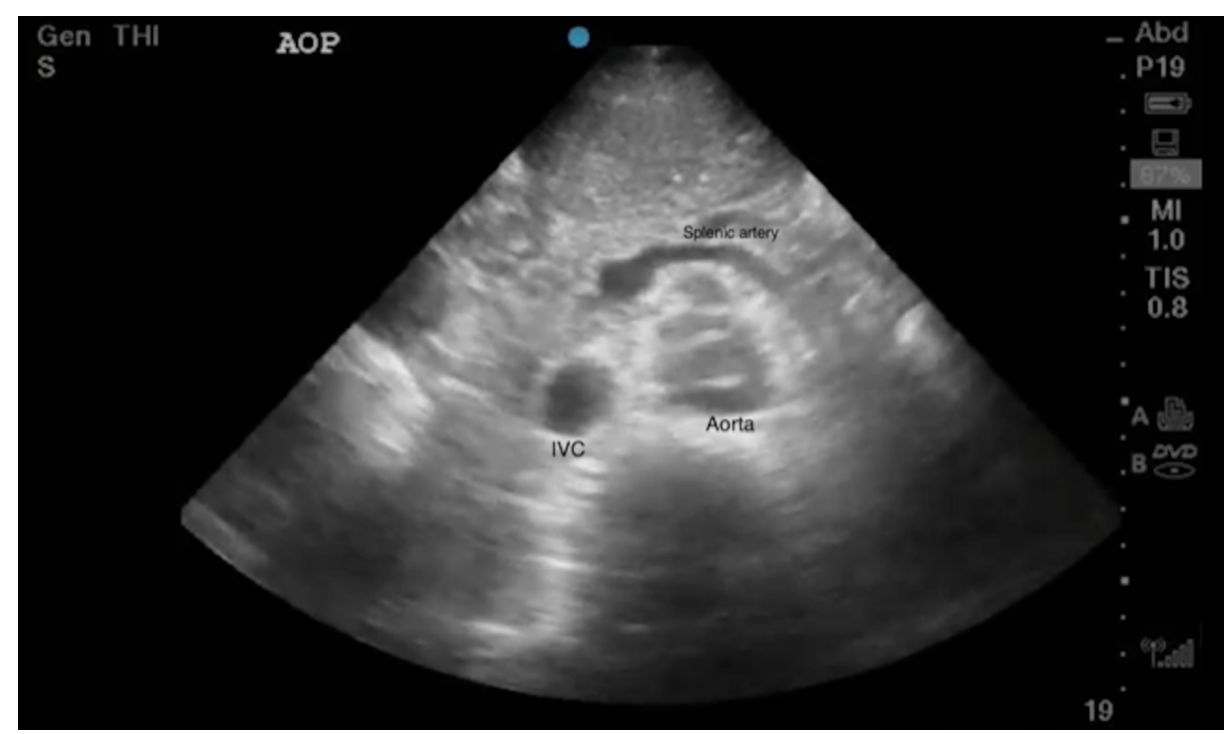

FIGURE 3: Transverse ultrasound image of intimal flaps in the aorta from a dissection

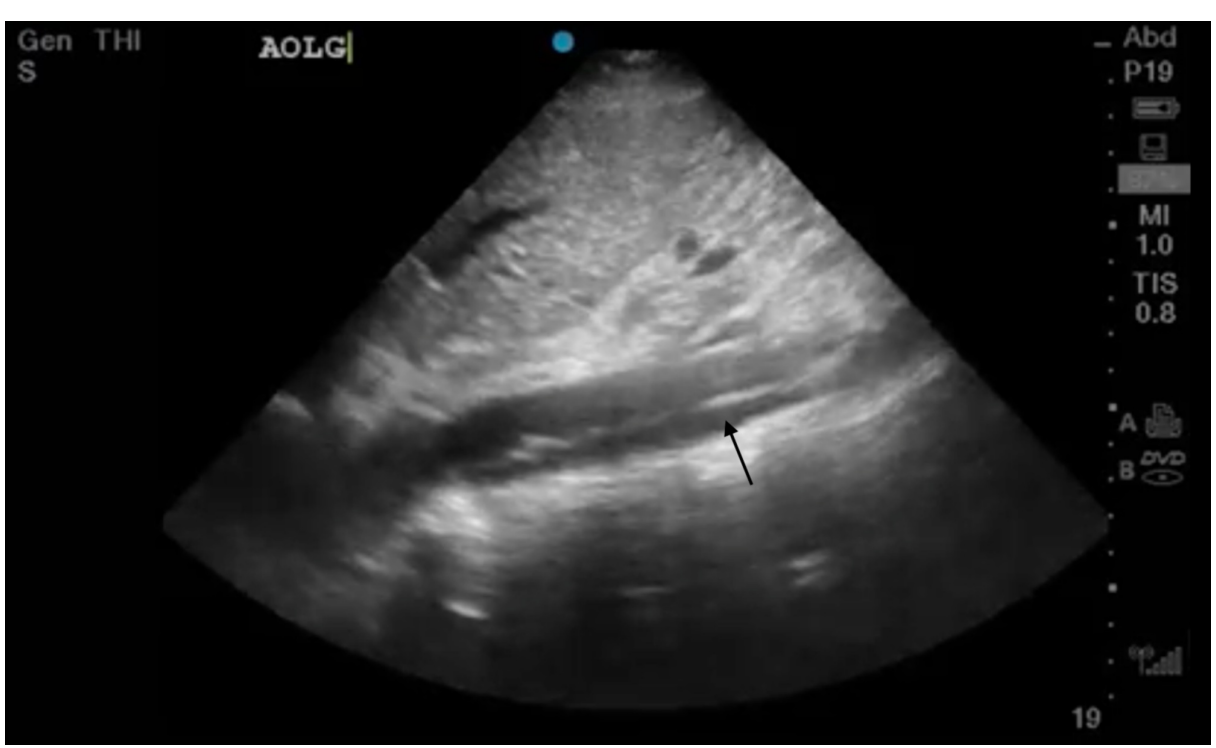

FIGURE 4: Longitudinal ultrasound image of intimal flap in abdominal aorta

No effusions or right heart strain was noted. The patient was taken emergently to CT scan, and the results were discussed with the radiologist over the phone immediately. This information was then relayed to the cardiothoracic surgeon.

The CTA chest and abdomen/pelvis showed a Stanford type A aortic dissection (Figures 5, 6). 


\section{Cureus}

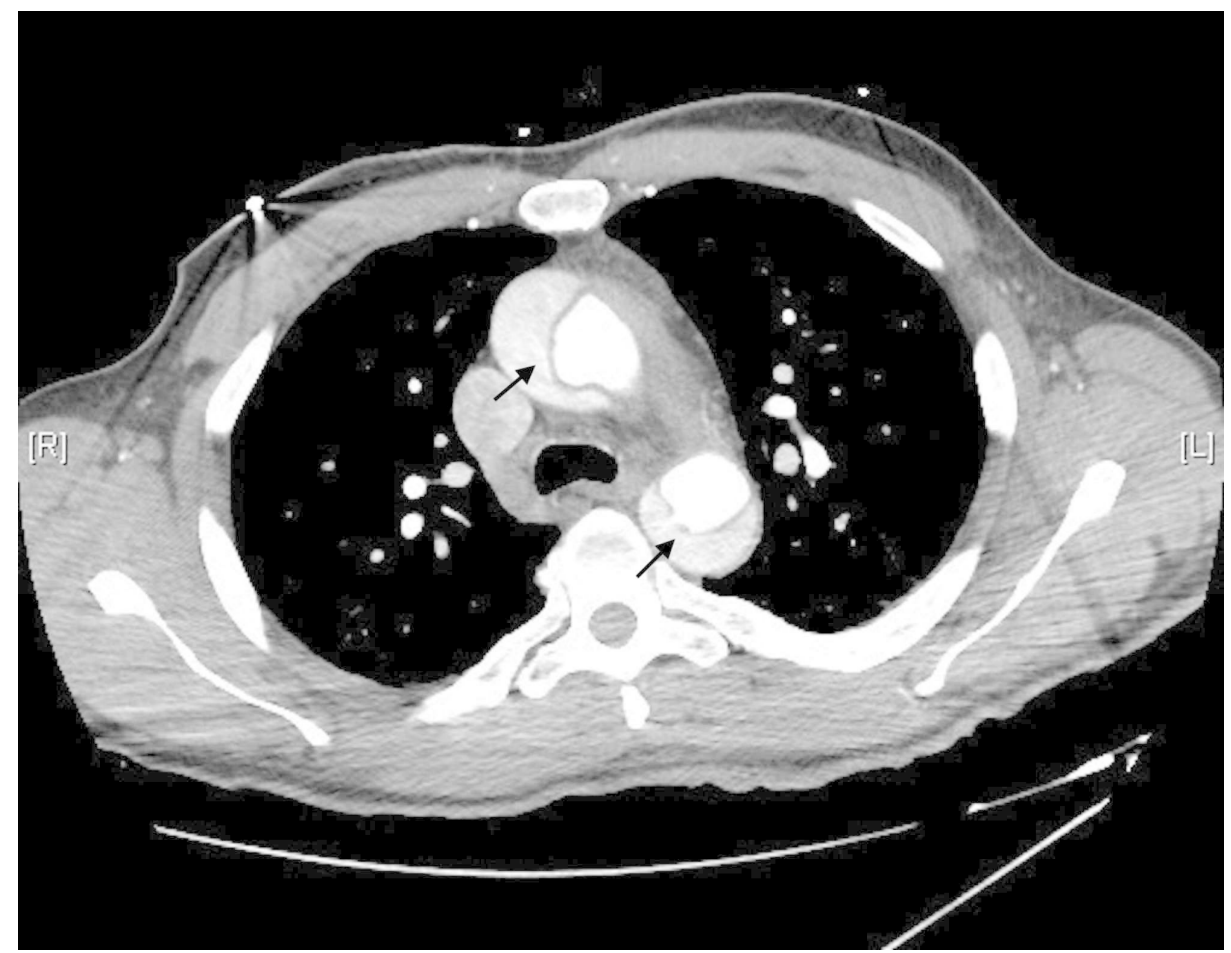

FIGURE 5: CT image of intimal flaps in ascending and descending aorta $\mathrm{CT}$, computed tomography

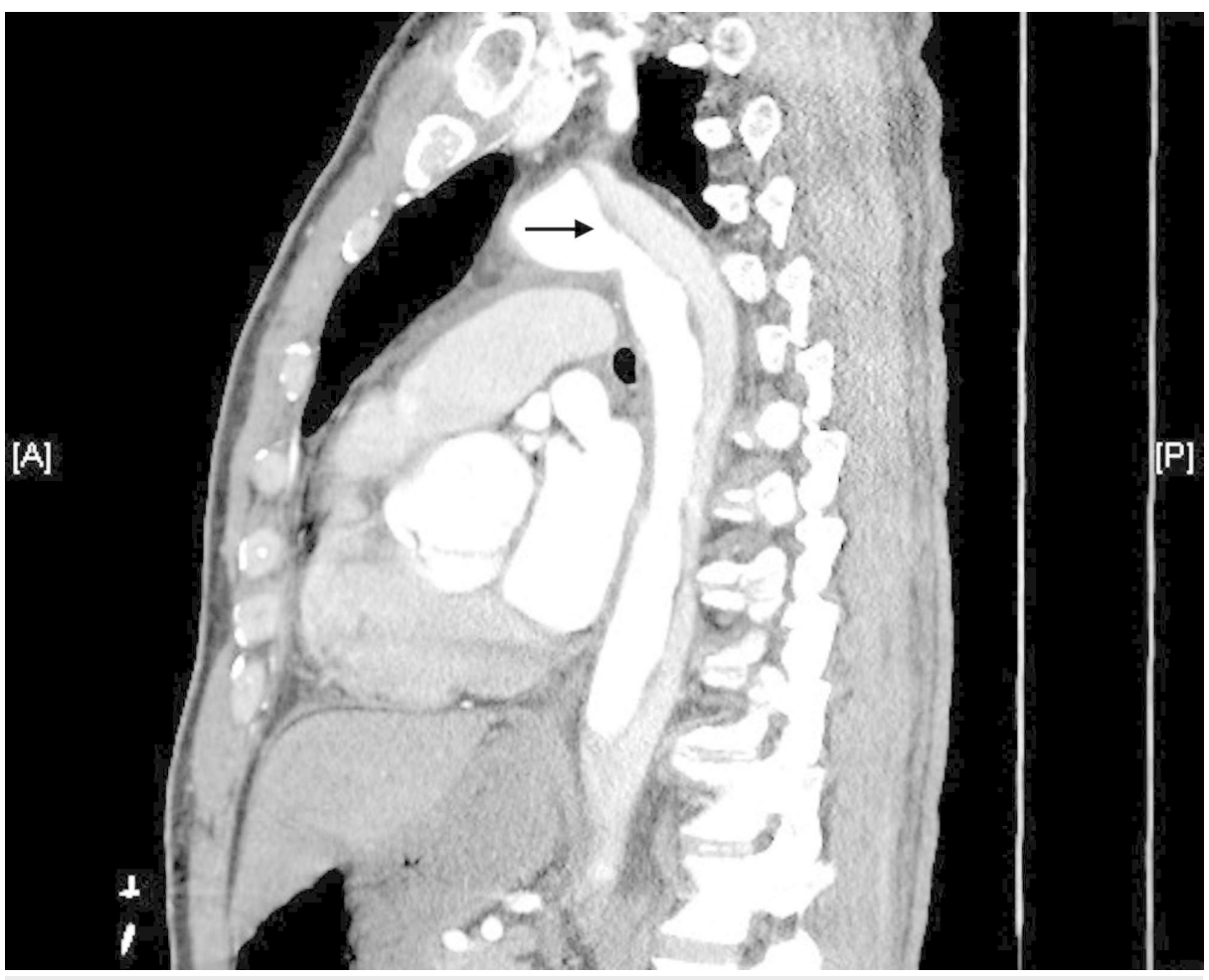

FIGURE 6: Sagittal CT view of aortic dissection

$\mathrm{CT}$, computed tomography 


\section{Cureus}

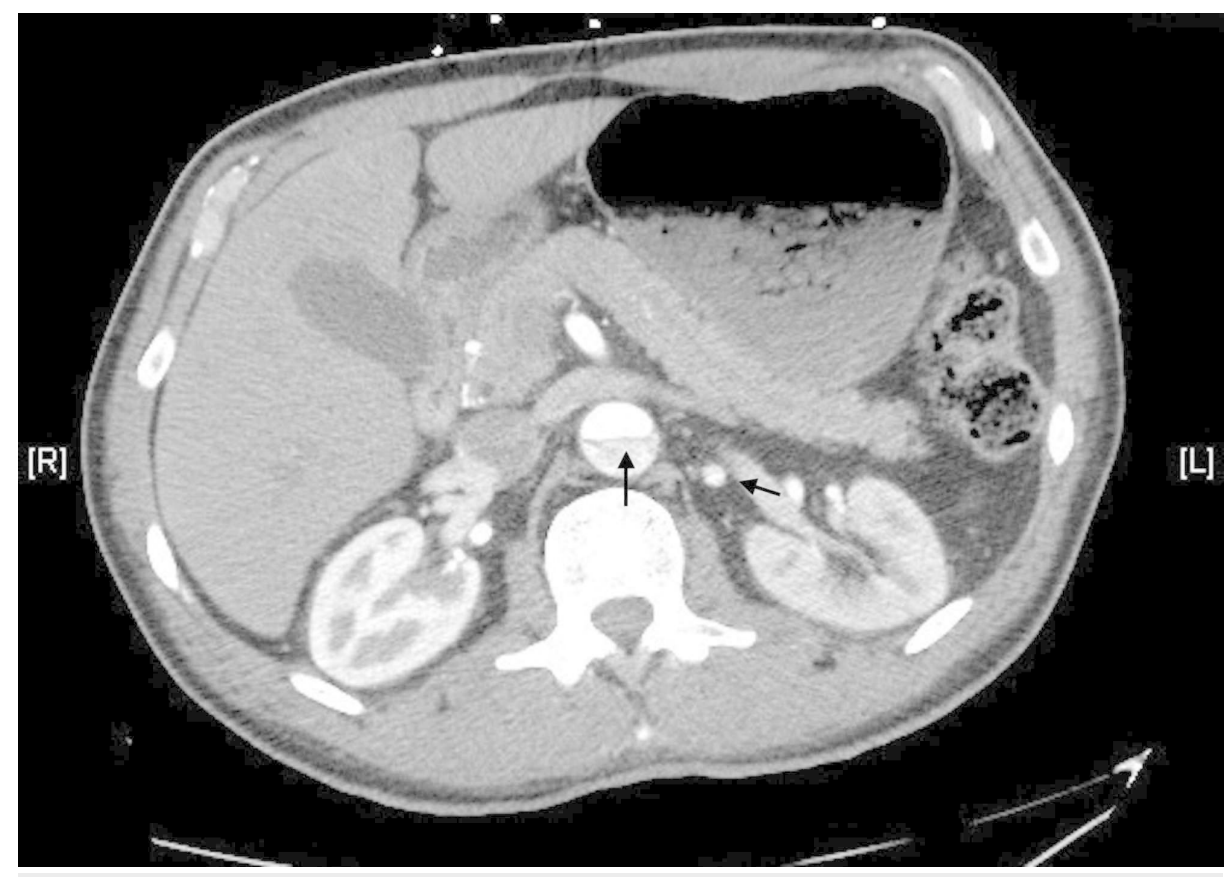

FIGURE 7: CT image of dissection extending to distal abdominal aorta and iliac artery

$\mathrm{CT}$, computed tomography

The dissection also extended into the right brachiocephalic artery and proximal right common carotid artery. The ascending thoracic aortic aneurysm measured up to $4.8 \mathrm{~cm}$, and the proximal descending thoracic aortic aneurysm measured up to $3.9 \mathrm{~cm}$.

The cardiothoracic surgeon immediately reviewed the images and took the patient for an emergent aortic dissection repair with a 32-mm hemashield graft placed and resuspension of the aortic valve. He was discharged 10 days later to a cardiac rehabilitation facility after an unremarkable postoperative course.

\section{Discussion}

The high morbidity and mortality of aortic dissections make methods of the timely diagnosis of this emergency an important consideration. The gold standard imaging for the diagnosis of an acute aortic syndrome (AAS) remains imaging with CTA, magnetic resonance angiography (MRA), or transesophageal echocardiography (TEE) with CTA the study of choice in the ED [5]. D-dimer testing has been studied as a way to rule out AAS when there is low clinical suspicion using the aortic dissection detection (ADD) risk score, but it has not been externally validated [6]. Our patient had a significantly elevated d-dimer that necessitated additional chest imaging. Given the high clinical suspicion, CTA could have been performed immediately.

The initial facility did not have the ability to perform CTA when the patient presented. Bedside TTE is an important diagnostic tool for resource-poor facilities in patients with chest pain. Our patient presented with hypotension, and a bedside TTE can quickly evaluate for not only pericardial effusions and heart strain but also aortic dissection as with our patient. The focus of emergency management of aortic dissection is traditionally heart rate and blood pressure control; however, hypertension is seen acutely in only 25 to 35 percent of type A dissections with hypotension present in 25 percent [3]. Causes could include acute aortic valve regurgitation, cardiac tamponade, acute myocardial ischemia, or aortic rupture and exsanguination $[3,7]$. Bedside ultrasonography is a valuable tool to identify and intervene in these complications $[5,8]$.

There are few quality studies addressing the use of bedside TTE by trained emergency physicians at this time. Most recommend its use as a rapid triage tool $[5,7,9]$. It can also be considered in patients with renal dysfunction or contrast allergies [7]. The American College of Emergency Physicians (ACEP) clinical policy for suspected acute nontraumatic thoracic aortic aneurysm did not recommend using bedside TTE to establish a definitive diagnosis as a level B recommendation, but they do recommend surgical consultation or transfer to a higher level of care if the TTE is suggestive of aortic dissection as a level C recommendation [10]. Further research is needed to determine the accuracy and limitations of bedside TTE. 


\section{Conclusions}

Acute aortic dissections are true emergencies where rapid intervention is necessary. The diagnosis is complicated by variations in presentation, the potentially time-consuming process of imaging, or serious contrast allergies. A suggestive bedside TTE can identify emergent complications and expedite further imaging, consultation, and transfer as needed. With further development of emergency physician ultrasound skills and research, its utilization could become a more fundamental part of aortic dissection diagnosis and management.

\section{Additional Information \\ Disclosures}

Human subjects: Consent was obtained by all participants in this study. Conflicts of interest: In compliance with the ICMJE uniform disclosure form, all authors declare the following: Payment/services info: All authors have declared that no financial support was received from any organization for the submitted work. Financial relationships: All authors have declared that they have no financial relationships at present or within the previous three years with any organizations that might have an interest in the submitted work. Other relationships: All authors have declared that there are no other relationships or activities that could appear to have influenced the submitted work.

\section{References}

1. Melvinsdottir IH, Lund SH, Agnarsson BA, et al.: The incidence and mortality of acute thoracic aortic dissection: results from a whole nation study. Eur J Cardiothorac Surg. 2016, 50:1111-1117. 10.1093/ejcts/ezw235

2. Clouse WD, Hallett JW Jr, Schaff HV, et al.: Acute aortic dissection: population-based incidence compared with degenerative aortic aneurysm rupture. Mayo Clinic Proc. 2004, 79:176-80. 10.4065/79.2.176

3. Hagan PG, Nienaber CA, Isselbacher EM, et al.: The International Registry of Acute Aortic Dissection (IRAD): new insights into an old disease. JAMA. 2000, 283:897-903. 10.1001/jama.283.7.897

4. von Kodolitsch Y, Schwartz AG, Nienaber CA, et al.: Clinical prediction of acute aortic dissection. Arch Intem Med. 2000, 160:2977-82. 10.1001/archinte.160.19.2977

5. Nienaber CA: The role of imaging in acute aortic syndromes . Eur Heart J Cardiovasc Imaging. 2013, 14:1523. 10.1093/ehjci/jes215

6. Nazerian P, Mueller C, Soeiro AM, et al.: Diagnostic accuracy of the aortic dissection detection risk score plus D-dimer for acute aortic syndromes: the ADvISED prospective multicenter study. Circulation. 2018, 137:250-258. 10.1161/CIRCULATIONAHA.117.029457

7. JCS Joint Working Group: Guidelines for diagnosis and treatment of aortic aneurysm and aortic dissection (JCS 2011): digest version. Circ J. 2013, 77:789-828. 10.1253/circj.cj-66-0057

8. Nallamothu BK, Mehta RH, Saint S, et al.: Syncope in acute aortic dissection: diagnostic, prognostic, and clinical implications. Am J Med. 2002, 113:468-71. 10.1016/s0002-9343(02)01254-8

9. Nazerian P, Vanni S, Castelli M, et al.: Diagnostic performance of emergency transthoracic focus cardiac ultrasound in suspected acute type A aortic dissection.. Intern Emerg Med. 2014, 9:665-70. 10.1007/s11739014-1080-9

10. American College of Emergency Physicians Clinical Policies Subcommittee (Writing Committee) on Thoracic Aortic Dissection, Diercks DB, Promes SB, et al.: Clinical policy: critical issues in the evaluation and management of adult patients with suspected acute nontraumatic thoracic aortic dissection. Ann Emerg Med. 2015, 65:32-42. 10.1016/j.annemergmed.2014.11.002 